\title{
pombalina
}

(8)

\section{As festas dionisíacas e a Pólis: novos espaços}

Autor(es): $\quad$ Acker, Clara Britto da Rocha

Publicado por: Centro de Estudos Clássicos e Humanísticos; Imprensa da Universidade

URL

persistente: URI:http://hdl.handle.net/10316.2/31515

DOI: $\quad$ DOI:http://dx.doi.org/10.14195/978-989-8281-20-3_5

Accessed : $\quad$ 26-Apr-2023 12:51:13

A navegação consulta e descarregamento dos títulos inseridos nas Bibliotecas Digitais UC Digitalis, UC Pombalina e UC Impactum, pressupõem a aceitação plena e sem reservas dos Termos e Condições de Uso destas Bibliotecas Digitais, disponíveis em https://digitalis.uc.pt/pt-pt/termos.

Conforme exposto nos referidos Termos e Condições de Uso, o descarregamento de títulos de acesso restrito requer uma licença válida de autorização devendo o utilizador aceder ao(s) documento(s) a partir de um endereço de IP da instituição detentora da supramencionada licença.

Ao utilizador é apenas permitido o descarregamento para uso pessoal, pelo que o emprego do(s) título(s) descarregado(s) para outro fim, designadamente comercial, carece de autorização do respetivo autor ou editor da obra.

Na medida em que todas as obras da UC Digitalis se encontram protegidas pelo Código do Direito de Autor e Direitos Conexos e demais legislação aplicável, toda a cópia, parcial ou total, deste documento, nos casos em que é legalmente admitida, deverá conter ou fazer-se acompanhar por este aviso.

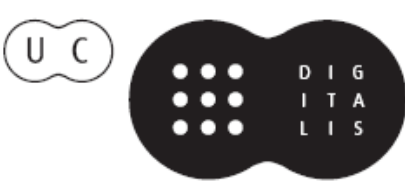




\section{Representações da Cidade Antiga}

categorias históricas e discursos filosóficos

\section{Gabriele Cornelli (Org.)}




\title{
As FESTAS DIONISÍACAS E A PÓLIS: NOVOS ESPAÇOS
}

The Festivals of Dionysus and the polis: New Spaces

Clara Britto da Rocha Acker ${ }^{1}$

\begin{abstract}
Resumo: Este artigo pretende tratar de algumas festas em honra ao deus Dioniso, como as Antestérias, momentos de importantes transgressões no espaço urbano. Durante essa festa, o deus tinha relações sexuais simbólicas com a representante de todas as mulheres de Atenas, a basilinna, revelando sua oposição à deusa Hera e à instituição do casamento. Essa oposição já aparece na mitologia e está presente também no teatro grego. Muitas tragédias mostram mulheres que valorizam a maternidade mais do que o casamento e algumas comédias, baseando-se nessa premissa, mostram-nas defendendo a paz, o comunitarismo e o feminismo. Assim a perspectiva dionisíaca redistribui o espaço cívico e transforma as estratégias de poder, trazendo à luz novos espaços, éticos e políticos.
\end{abstract}

Palavras-chave: Dioniso, festas, mulheres, ética, política.

Abstract: This paper wants to deal with some festivals in honor to the god Dionysus, such as the Anthesteries, moment of important transgressions in urban space. During this festival, the god had symbolic sexual intercourse with the basilinna, which represented all Athenian women, revealing his opposition to the goddess Hera and to the institution of marriage itself. This opposition appears already in mythology and is also present in Greek theater. Several tragedies show women, which give more value to maternity than to marriage and some comedies, based on this premise, show them defending peace, comunitarism and feminism. Therefore, dionysiac perspective redistributes civic space, transforming the strategies of power, bringing to light new spaces, ethical and political.

Keywords: Dionysus, festivals, women, ethic, politic.

A religião grega intriga e espanta por algumas de suas manifestações e, particularmente, alguns rituais e festas em honra ao deus Dioniso, como as Antestérias, uma das mais antigas festas a Dioniso, comemorada em várias cidades gregas. Por outro lado, as representações teatrais, incluídas no complexo ritual mais amplo das Dionísias ou das Lenéias, contêm textos, que apesar de aparentemente, nada terem em comum com Dioniso, possuem como pretendemos demonstrar, uma relação íntima com os mitos dionisíacos. Essas duas manifestações do culto rompem não somente com o espaço político, mas igualmente com outro espaço, aquele reservado à alma, legitimando a crítica às estratégias de poder vigentes na Grécia clássica.

Quais as relações entre o culto dionisíaco e a pólis? Qual o significado dessas festas e rituais? Existe uma filosofia propriamente dionisíaca? E qual seria ela? Vamos tentar responder a essas perguntas por meio da interpretação simbólica dos dados rituais relatados pelas fontes e de uma análise de alguns textos de peças teatrais trágicas e cômicas.

${ }^{1}$ Doutora em Filosofia (Paris IV-Sorbonne). 
As Antestérias, festa das flores, são consideradas as mais antigas festas em honra a Dioniso e durante três dias Atenas se transformava, com a participação de todos os seus habitantes, no palco de uma série de transgressões, que culminavam em uma união sagrada entre Dioniso e a "rainha" de Atenas (Âr., Ath. Pol., III, 5).

Chegando a Atenas por mar, a estátua do deus era transportada num barco sobre rodas, num cortejo que a acompanhava até o único santuário aberto naquele dia, o templo de Dioniso do Pântano (D., Contra Neera, 73 e 75). Escravos e homens livres participavam de um concurso de beberagem, que acontecia em pleno centro da vida política ateniense, no Thesmothéteion (Plu., Quaest. Conv., I, 1, 2). É no templo do Pântano, que a basilinna vai oferecer um sacrifício secreto, sobre 14 altares diferentes, sendo auxiliada por 14 mulheres. A relação entre esse sacrifício e o mito egípcio das 14 partes de Osíris desmembrado já foi notada por Paul Foucart (1904: 139-140) e confirma os laços entre Dioniso e Osíris, assinalados desde a Antiguidade por Heródoto (Histórias, II) e Plutarco (De Is. et Os., 364). O corpo desmembrado de Osíris era primeiro reunido, pedaço por pedaço e depois, reconstituído por Ísis. O sacrifício praticado durante a festa dionisíaca possui segundo Plutarco, relações com os 14 dias de declínio da lua. É como se o animal sacrificado fosse oferecido sobre 14 altares, em 14 pedaços, designando o desmembramento, o declínio e a morte. Após esse sacrifício, Dioniso vai se unir à basilinna em plena ágora, ao lado do Prytaneu, no Boukoleion, um estábulo, que era também a antiga casa do Arconte-Rei (Ar., Ath. Pol., III, 5), um magistrado da cidade democrática, designado por sorteio, cujo nome de basileus indica funções mágicas e sacerdotais. Essa união secreta devia respeitar certas modalidades, impostas pelo conjunto de cidadãos e gravadas sobre uma stela, conservada no templo de Dioniso do Pântano (D., Contra Neera, 73 e 75). A basilinna, imbuída de poder e de funções cultuais importantes, simbolizava, durante as Antestérias, todas as mulheres de Atenas (Jeanmaire, 1951: 51-52). Por meio dessa união sexual simbólica com Dioniso, a basilinna garantia a fertilidade de todas as mulheres de Atenas. $\mathrm{O}$ aspecto fecundante de Dioniso taurino aparece aqui como uma necessidade para a pólis e como uma responsabilidade de basilinna. Investindo os espaços políticos, Dioniso touro chega como um conquistador vindo do mar e se une à representante de todas as mulheres da cidade, uma sacerdotisa. Estamos lidando aqui com o poder de ressurreição atribuído à mulher e à lua. A mulher e a lua mostram em seus corpos, sobre a terra e no céu, como num palco, a possibilidade do invisível se tornar visível. As 14 partes desmembradas do deus serão reunificadas pela basilinna, que, assim, vai poder gerá-lo de novo simbolicamente. Do não ser ao ser, a lua-mulher detém caminhos misteriosos e fecundantes, sem os quais não há vida. Podemos pensar em Ísis e em como a deusa conseguiu a notável façanha de gerar um filho póstumo de Osíris, Horus.

Cabe ressaltar que a união entre Dioniso taurino e a basilinna não era considerada como paradigma para os casamentos, sendo esses relacionados com a bierogamia entre Zeus e Hera, a deusa do casamento enquanto instituição 
política (Daraki, 1994: 80). O casamento grego na época clássica tinha por fim o estabelecimento de critérios de distinção entre filhos legítimos e bastardos (Daraki, 1994: 75) e era um acordo econômico entre famílias, concluído entre os homens. Dioniso, no entanto, simboliza em seus rituais a figura do amante e não a do marido (Hoffmann, 1990: 59-63), confirmando o profundo antagonismo que o separa de Hera desde a mitologia. Ao possuir a basilinna, Dioniso reitera a união entre Zeus e Sêmele, da qual ele mesmo é o fruto. Deus e filho ilegítimo, Dioniso vem dissociar fecundidade e casamento, indicando para as mulheres o valor intrínseco da maternidade.

Às moças jovens também era dada maior liberdade durante a festa dionisíaca: elas se balançavam nesse dia, recitando versos obscenos, como que rompendo com o tempo profano e inaugurando a exceção do tempo sagrado para sua faixa etária. A adolescência das mulheres, a primeira menstruação, marca o tempo de começar a participar do culto dionisíaco (Jeanmaire, 1951: 208).

Os meninos acima de três anos recebiam seu primeiro copinho de vinho (choes) e eram assim integrados à festa, possuídos por dentro como seus pais, pelo líquido dionisíaco (Daraki, 1994: 85-87).

O terceiro e último dia da festa, denominado Chytroi (marmitas) era consagrado aos seres do além. Neste dia cada família preparava uma marmita de grãos para seus mortos. Oferecido esse alimento, era pedido aos seres que se fossem até o ano seguinte. Como não pensar no fragmento de Heráclito que declara serem Dioniso e Hades o mesmo deus (Heraclit., frag. 15)?

Dioniso invadia assim importantes espaços políticos e sagrados, promovendo a transgressão de todas as fronteiras em todas as camadas da população, chegando a abranger o reino dos mortos. Assim toda a pólis participava ativamente da festa das flores, cada camada da população recebendo Dioniso como melhor lhe convinha, pelo vinho ou através do aspecto fecundante do touro. No ritual das Antestérias, a pólis está em transe.

Já durante os Concursos teatrais, a cidade assiste às representações em um espaço limitado pelo teatro, e estas obedecem a um texto sempre novo a cada ano. Como estes textos se relacionavam com Dioniso, muitos antigos já não o percebiam, mas se aceitarmos os dados fornecidos pela mitologia e particularmente a oposição entre Dioniso e a deusa do casamento, Hera, o essencial se desvenda diante de nossos olhos (Acker, 2002:31-60). Muitas peças trágicas levam o nome de mulheres e, algumas vezes, o nome do coro de mulheres. Ainda que nenhuma mulher tenha subido num palco antigo como atriz, os textos pronunciados em nome das mulheres nas tragédias são muito significativos, atacando por diversas vezes frontalmente a instituição do matrimônio e valorizando, acima desse, a maternidade (E. Med. e I.A.; Soph. Ter; A. Supp.) Assim, durante as tragédias, assistimos ao mesmo tempo, à crítica às instituições políticas por meio da crítica ao casamento e à criação de um espaço de reflexão sobre o sentido ético e político da maternidade (Acker, 2002: 235-327).

Nenhuma outra oposição aparece de forma tão nítida na Oréstia quanto aquela entre os valores guerreiros defendidos por Agamêmnon e os valores da 
maternidade defendidos por Clitemnestra (Acker, 2002: 261-273). Orestes e Electra tomam o partido do pai e do casamento, mesmo que este tenha sido o fruto de uma série de violências contra Clitemnestra (E., $L A, 1149-1152$ ). Para absolver Orestes do crime de matricídio, será preciso a intervenção de Apolo, que dirá ser a mãe apenas um depósito do germe vivo do pai (A., Eum., 658-666). O voto da deusa Atena dará o benefício do empate a Orestes, consagrando uma nova era.

Chama a atenção, por outro lado, o fato de que as Danaidas, personagens principais das Suplicantes de Ésquilo, obtêm, na cidade de Argos, cuja deusa protetora é Hera (Hom., Il., IV, 51), o direito à recusa ao casamento, pelo voto unânime de homens que bebem vinho (E., Sup., 940-954). Segundo Pausânias (Descrição da Grécia, II, 37), as Danaidas ofereceram uma imagem em madeira, dedicada a Dioniso Saoter (salvador). Os homens que bebem vinho aceitam o feminino dionisíaco dentro de si e votam, para dar às Danaidas, o direito de recusar um casamento violento. É, portanto, natural que, em agradecimento, essas tenham oferecido uma imagem a Dioniso.

As Suplicantes, de Eurípides, cujo coro é composto por mães anciãs, declaram que o verdadeiro mal não é o de ignorar as núpcias, mas, sim, o de perder seus filhos (E., Sup., 786-788).

Dionisíaca também é a filosofia de Antígona, que, em nome dos costumes ligados ao ventre (bomosplanchnous sebein) (S., Ant., 511), defende o direito de enterrar seu irmão, ainda que este seja considerado um traidor pela pólis tirânica de Creonte. Nenhum acaso pode haver no fato de Eurípides ter designado Antígona como uma Bacante, que não somente participou dos cortejos dionisíacos, mas os conduziu (E., Ph., 1751-1756).

Para Andrômaca, seu filho, mesmo ilegítimo aos olhos da pólis, é o olho de sua vida (E., Andr., 406). Para Hécuba, sua filha é sua alegria, o esquecimento de seus males e também a pátria, a nutriz, o cajado e o guia (E., Hec., 277-281). A criança torna-se, deste modo, o maior valor, que prima absolutamente sobre a pólis, como bem percebeu Nicole Loraux (1990: 64). Esse enfoque dionisíaco sobre a vida tem implicações políticas importantes numa cidade-estado guerreira como Atenas, pois a defesa da maternidade é imediatamente uma defesa da paz. Mesmo no espaço limitado de um teatro, Dioniso rompe com os valores políticos vigentes, alarga as perspectivas e abre na alma dos cidadãos espectadores uma compreensão profunda sobre o valor sagrado da vida.

Como se tal não bastasse e como Dioniso fechava as representações com as comédias, dois textos de Aristófanes nos mostram uma espécie de ideologia política, atribuída às mulheres. Lisistrata e a Assembléia das Mulheres nos mostram mulheres resolutamente pacifistas, claramente conscientes da ganância dos donos do poder, dispostas a assumir seus deveres de cidadãs para a prosperidade comum. Ao prestar juramento a respeito da paz, Lisístrata sacrifica não um carneiro, mas um pote de vinho (Aristoph., Lys., 194-197), após ter invocado Bacchos (ibid., 1). Segundo Eurípedes, Dioniso ama a Paz, deusa que nutre a juventude (E., $B a ., 416-420)$. As personagens femininas de Lisistrata parecem ao Corifeu ter talento natural, graça, audácia, sabedoria 
e patriotismo unido à prudência (Ar., Lys., 541-548). Elas querem tecer um manto para o povo (ibid., 584-585) e lançar embaixadas para estabelecer o diálogo entre as partes (ibid., 568-570), ainda que para tal seja necessário beber vinho e deixar-se possuir pela visão dionisíaca. Lisístrata quer não somente proteger o povo, mas dar a ele o instrumento para que se proteja. A paz deve prevalecer acima de tudo, ainda que para tal seja preciso sacrificar a Razão. As estratégias de racionalização do conflito, devem se dissolver na seiva dionisíaca e no diálogo.

Em A Assembléia das Mulheres, Praxágoras também invoca Baco (Ar. Ec., 1-15), antes de dizer que sendo mães, as mulheres terão o maior interesse em salvar os soldados (ibid., 214-235). Decididas a tomar o poder político para realizar o bem comum (ibid., 105-108), num sistema amplamente comunitário, no qual todos os bens privados, principalmente a terra, serão postos em comum (ibid., 590-598), as mulheres vão nutrir o povo, administrando com economia e pensando em tudo (ibid., 598-600). A atividade política das mulheres encontra seu fundamento na maternidade e inclui a função de alimentação do povo. Praxágoras anuncia um sistema, no qual as mulheres poderão ter relações sexuais e filhos com quem quiserem (ibid., 612-614) e as crianças verão como pai qualquer homem mais velho (ibid., 636). A pólis será uma só habitação, após terem ruído todos os muros (ibid., 672-674).

A voz das mulheres se eleva no teatro para defender a maternidade e as leis não escritas, sobre as quais deve se erguer uma nova pólis: pacifista, acolhedora para os excluídos, comunitária, solidária e unida.

Vemos, dessa forma, que o culto dionisíaco é portador de uma mensagem ética e política de extrema atualidade: pacifista, feminista, comunista ou comunitária e, sem dúvida, ecologista. Por essas razões, acreditamos na urgência de um retorno à Grécia através de olhares femininos, que nos restituam os valores perdidos por mais de 2.500 anos de dominação e de perseguição. Evoé Dioniso! Evoé Bacantes!

\section{Bibliografia}

Acker, C. (2002). Dionysos em transe: la voix des femmes. Paris: l'Harmattan. Apollodoro, J. G. F. (1921). The Library. London: Harvard University Press. Aristófanes. (1966). A Assembléia das Mulheres. Paris: Les Belles Lettres.

Aristófanes. (1966). Lisistrata. Paris: Les Belles Lettres.

Aristóteles. (1972). Constitution d'Athènes. Paris: Les Belles Lettres.

Atheneu. (1956). Les Deipnosophistes. Paris: Les Belles Lettres.

Bennett, E. L.; Olivier, J. P. (1973). The Pylos Tablets Transcribed. Roma: Ateneo. 
Daraki, M. (1985; 1994). Dionysos et la déesse Terre. Paris: Flammarion.

Demóstenes. (1960). Contre Néera. Paris: Les Belles Lettres.

Ésquilo. (1925). Tragédies. Paris: Les Belles Lettres.

Eurípedes. (1956). Andromaque. Paris: Les Belles Lettres.

Eurípedes. (1956). Hécube. Paris: Les Belles Lettres.

Eurípedes. (1961). Les Bacchantes. Paris: Les Belles Lettres.

Eurípedes. (1923). Les Suppliantes. Paris: Les Belles Lettres.

Eurípedes. (1950). Les Phéniciennes.Paris: Les Belles Lettres.

Foucart, P. (1873). Des Associations Religieuses chez les Grecs: Thiases, Eranes, Orgéons, Paris: Klincksieck.

Foucart, P. (1904). Le Culte de Dionysos en Attique. Paris: Imprimerie Nationale.

Heródoto, (1936). Histories. Paris: Les Belles Lettres.

Héraclito. (1968). Die Fragmente der Vorsokratiker. Berlin: Diels-Kranz.

Hoffmann, G. (1990). Le Châtiment des Amants dans la Grèce Classique. Paris: De Boccard.

Hygino. (1997). Fables. Paris: Les Belles Lettres.

Jeanmaire, H. (1951). Dionysos, Histoire du Culte de Bacchus. Paris: Payot.

Loraux, N. (1990). Les Mères en Deuil. Paris: Seuil.

Plutarco. (1972). Propos de Table. Paris: Les Belles Lettres.

Sófocles. Tragédies. Paris: Les Belles Lettres. 